\title{
Dramaturgia hipertextual: ensayando la frontera
}

\section{Rocío Galicia}

Cartografía epocal. Una barda cae significando el fin de un Sistema. Otras bardas se erigen con la finalidad de obstaculizar la circulación de personas, pero facilitando, paradójicamente, el libre "tráfico" de objetos. Una pirámide de cadáveres en San Fernando (Tamaulipas) activa capítulos indecibles del pasado de la humanidad. Cae un asteroide en Sudán y astrónomos encuentran la sumatoria de diversos cuerpos celestes, pues en sus sedimentos está inscrita la historia de las colisiones que lo conforman. Al finalizar una partida de X-box, un niño "deambula" virtualmente por los cuerpos caídos, los cuales le otorgan una determinada puntuación y su pasaje al siguiente nivel. Una grabadora de audio, una memoria de datos, una cámara fotográfica y otra de video son introducidas en una "pluma-espía". Las anteriores imágenes quieren ilustrar momentos que reconfiguran certezas y visiones de la geopolítica, la historia, la ciencia y la tecnología. Nuestra mente reelabora los cambios a partir de esos y otros fragmentos de Realidad.

Consecuentemente, tiempo y espacio son repensados y complejizados. A decir de Hans-Thies Lehmann, "La manera de percibir se desplaza: una percepción simultánea y de perspectivas plurales reemplaza la percepción lineal y sucesiva" ("El teatro"). Este cambio de percepción habrá de impactar, por supuesto, a la escritura y la escena teatral. Si bien han existido excepciones o apuestas personales en México, un trabajo de conjunto que dé cuenta del viraje resulta más complicado localizar. No obstante, existe y se expande rizomáticamente. En los últimos diez años surgió y se fortaleció en la dramaturgia mexicana una conceptualización que no sólo rompe con la linealidad sino también con el pensamiento binario. Este corpus ha sido denominado dramaturgia hipertextual. Su soporte está en el trabajo de creación e investigación desarrollado por Enrique Mijares. 
El conjunto de obras que ha subvertido al canon desde hace algunas décadas se territorializó en el Norte de México. Las circunstancias que contribuyeron a su irrupción fueron múltiples; no sistemáticas, pero sí relacionales. Mi investigación sobre la dramaturgia norfronteriza me llevó a atestiguar la expansión y el fortalecimiento - también las críticas-de la dramaturgia hipertextual. A lo largo de este ensayo propongo comentar el proceso de surgimiento, esbozar los códigos de lenguaje y estructuras, así como referir algunos textos dramáticos que han sido escritos en los últimos diez años. Obras que a diferencia de sus predecesoras, hoy son producto de una búsqueda consciente por construir lenguaje y entablar un diálogo reflexivo y creativo con el espectador.

Armando Partida, quien ha estudiado a profundidad los modelos de acción dramática, señala: "en el siglo XX, sobre todo a partir de la segunda posguerra mundial, nos encontramos con la irrupción abierta de un cierto eclecticismo genérico y estilístico que ha privado en la dramaturgia desde entonces, lo cual ha venido a complicar el panorama de las definiciones a ultranza, hoy del todo obsoletas" (8). Más aun, el dislocamiento entre la producción dramática y el canon permite observar sus estrategias de permanencia, negociación y afianzamiento. A través de su máquina de reproducción (crítica y preceptiva), el canon dramático rechaza aquellas configuraciones que disienten de sus proposiciones. Es así que las aventuras del pensamiento son ignoradas o abiertamente rechazadas cuando no se ajustan a la norma.

Sin embargo, el canon dramático es una faz del canon original que rige el pensamiento. En el canon fundacional cualquier idea externa, por vanguardista que sea, es reducida a la lógica del pensamiento binario (bien-mal, negro-blanco, falso-verdadero, local-global, privado-público, capitalista-proletario, izquierda-derecha, protagonista-antagonista). Desde este emplazamiento puede entenderse la reducción que se ha llevado a cabo de las ideas subversivas de Freud, Marx y Nietzsche, denominados por Paul Ricoeur como "los maestros de la sospecha". Estos, desde su particular campo disciplinar, hicieron evidente el reinado de lo parcial. La lucidez de su crítica sobre la sociedad burguesa fue desestabilizadora del status quo. Paradójicamente, la mejor manera de minar su peligrosidad fue incorporándolos en el espacio de flexibilidad o juego del canon — obviamente, luego de un proceso de tergiversación y quebranto. Con este ejemplo intento mostrar que el canon es recursivo y que contempla como estrategia la asimilación aun de las críticas radicales. Así pues, la sobrevivencia del 
canon está apoyada en un fino mecanismo que engulle y neutraliza aquellas producciones intelectuales que podrían acabar con él.

En la dramaturgia, el modelo imperante sostuvo por siglos la lógica del pensamiento binario. Su formulación tuvo como centro al conflicto, el cual supone la contraposición y el enfrentamiento de fuerzas. Aprendimos en nuestras clases de teoría la centralidad del conflicto: "el conflicto es el motor del drama". A tal esquema se le sumaron el respeto irrestricto a las "unidades aristotélicas", la linealidad cronológica, el desenlace cerrado, la incorporación de una guía de montaje a través de las acotaciones, la estructuración en planteamiento, nudo y desenlace, la intención de crear personajes singulares, la búsqueda a priori de la "universalidad" y, finalmente, la exégesis del mensaje del autor. Ese modelo dramático si bien produjo obras maestras, hoy poco o nada tiene que ver con el régimen de vida y los intereses de quienes acuden a presenciar los espectáculos teatrales.

El siglo XXI no sólo ha diversificado las formas de creación, sino también ha cuestionado y redistribuido los roles autorales. La dramaturgia ha dejado de ser el terreno específico del autor teatral para repensarse en ámbitos como el actoral, el dancístico o de las imágenes. Han surgido otras formulaciones que ponen en el centro al cuerpo y tensionan al lenguaje y la representación. De ello han hablado en los últimos años Helga Finter, Ileana Diéguez, Hans-Thies Lehmann y José Sánchez. Sus análisis nos llevan a cuestionar el estatuto de la producción textual en nuestro tiempo. Por otra parte, se ha notado que el umbral de atención y la capacidad anticipativa de los espectadores se ha ido transformando debido a la vertiginosidad que caracteriza a nuestra época. Las narrativas televisivas y cinematográficas, la inmediata circulación de información y la constante aparición de avances tecnológicos no sólo han modificado nuestra percepción sino también nuestros hábitos y consumos. Es así que las parafernalias escénicas montadas en elefantes blancos y las formas teatrales anquilosadas respecto a su construcción dramática están sufriendo del abandono del público.

Ya desde el siglo pasado Antonin Artaud había criticado duramente las manifestaciones de un teatro al que describía como muerto. Decía que si el "vulgo" no acude a las obras maestras literarias es porque estas son fijas y no corresponden a las necesidades de los tiempos. La culpa estaba, según él, en la interposición de una valla formal y en la idolatría hacia las obras maestras estáticas. Por su parte, Jacques Derrida advierte que la escena teológica, "comporta, siguiendo toda tradición, los elementos siguientes: un autor-creador que, ausente y desde lejos, armado con un texto, vigila, 
reúne y dirige el tiempo o el sentido de la representación, dejando que ésta lo represente en lo que se llama el contenido de sus pensamientos, de sus intenciones y de sus ideas" (322). En concordancia con ambos, hay creadores que impugnan también la cerrazón de los discursos dramáticos y buscan propiciar el diálogo con los espectadores, a quienes incluso los consideran como coautores del acto literario o escénico. Si bien en nuestro campo siguen existiendo autores que defienden a ultranza cada palabra y cada signo fijado en el texto, también es cierto que otros están más interesados en conformar un teatro abierto a la reflexión y al diálogo. Esta es la intencionalidad de la dramaturgia hipertextual.

\section{Génesis y conceptualización}

Un cambio de rumbo en la dramaturgia mexicana fue advertido en 1996 por Enrique Mijares. El análisis de Las perlas de la virgen de Jesús González Dávila derivó en el hallazgo de códigos de lenguaje que significaron un rompimiento con la lógica binaria arraigada en el conflicto y en la exposición lineal de los acontecimientos. González Dávila, según el análisis de Mijares, rompió con la construcción de personajes de una densa psicología y singularidad como única vía para hacer empatía con el espectador. Más aun, en Las perlas de la virgen Polo y Ross son personajes que se abren, se multiplican y resultan al mismo tiempo diversas facetas de uno mismo. La anécdota es mínima y lo que el espectador tiene frente a sí es una virtualización de las posibilidades que tienen estos personajes antes de comenzar un viaje por el desierto. Las acciones se diversifican y el dilema permanece latente en cada una de las escenas. Así, la obra ofrece una visión panorámica del hombre en la frontera.

Las perlas de la virgen generó reflexiones que consolidaron un campo teórico sobre el teatro fronterizo. A través de esta mirilla fueron dilucidas obras de Antonio González Caballero, Hugo Salcedo, Medardo Treviño y otros dramaturgos del norte de México. Este análisis llevó a Mijares a publicar en 1999 el libro La realidad virtual del teatro mexicano. El concepto aglutinador fue el "realismo virtual", oxímoron que establece la tensión entre la realidad fáctica y la virtualización de un sinnúmero de opciones. La exposición, por tanto, implica diversificación que deviene en el entendimiento de la complejidad. Para Mijares, la virtualización permite ver por anticipado las consecuencias que podría generar una actitud o la opción que elegimos. En Las perlas de la virgen la virtualidad es muy clara: cada cuadro, cada escena es una opción que se pone en marcha y que termina fatalmente. "Al final, 
cuando los dos personajes están parados junto a la orilla de la carretera a punto de emprender la aventura es que han considerado todas las opciones, y ahora sí, pueden emprender el camino con cierta reflexión sobre lo que puede pasar, lo cual nunca sabemos de cierto, pero se ha virtualizado. Es decir, se ha simulado cómo sucedería" (Mijares, Entrevista). Las constantes formales mencionadas en el libro son: intertextualidad, collage, personajes múltiples, fragmentación, fractalidad, hipertextualidad, deconstrucción y discontinuidad, entre otras. Esta enunciación podría suponer un paralelismo con el teatro posmoderno, pero de inmediato Mijares advierte que son recursos que con anterioridad han sido empleados en mayor o menor grado para dar vida o matizar otras corrientes estéticas. Más allá de la forma, el realismo virtual ha tenido como objetivo la generación de un ejercicio de reflexión sobre las problemáticas actuales.

Al paso de los años el realismo virtual fue derivando hacia las estructuras hipertextuales. Es decir, el dilema inicial fue conformando su estructura. La virtualidad entraña la maleabilidad de la convención: qué pasaría si.... En contraste, el hipertexto implica estructura. Consecuentemente, el texto teatral no es concebido más como el espejo plano que devuelve una imagen, una figura. ¿Qué mecanismo entonces propone la dramaturgia hipertextual? Según la física cuántica, la luz no sólo puede sino debe estar en varios lugares a la vez. Así, no es el reflejo sino el fenómeno de refracción lo que se busca plasmar desde esta dramaturgia. Un haz de luz al atravesar un prisma se descompone en un espectro de colores, es decir, produce diversificación. Así mismo las estructuras de las obras buscan mostrar la multiplicidad de opciones que supone el dilema.

Ahora bien, el rompimiento con el conflicto como generador del drama, por su condición desestabilizadora y polémica, merece una amplia explicación:

[El conflicto] creo que es la zanahoria frente a la nariz de la que se han aprovechado las hegemonías políticas, religiosas, administrativas para catequizar y controlar a los ciudadanos, a los correligionarios, a los subalternos para, por un lado, homogeneizarlos, masificarlos, globalizarlos... y por otro, obligarlos a enfrentarse unos con otros, a luchar, a hacer la guerra, al grito maniqueo de "El que no esté conmigo está contra mí", slogan que curiosamente tiene su origen en la palabra de aquel a quien se atribuye la redención del hombre y a quien se anuncia como el gran conciliador. En la medida que es el eje de una concepción binaria del mundo, el conflicto como 
tal, hace más de medio siglo que tiende a desaparecer, por más que las escuelas y talleres de dramaturgia se empeñen en sostener que sin él no existe teatro alguno. Muchas veces he advertido a los teatreros acerca del peligro de radicalizar las posturas, de polarizar las opiniones y pretender dar lecciones a través de los desenlaces cerrados. (Galicia 191)

El fragmento anterior es revelador de la ruptura no sólo con la estructura dramática clásica, sino con la ideología dominante. Lo expuesto en estas líneas es medular para observar la crítica que Mijares hace a la dramaturgia afincada en el conflicto. En efecto, éste es señalado como oposición, pugna o enfrentamiento de fuerzas antagónicas, ya sea entre los hombres o de estos con la divinidad. ${ }^{1}$

En la obra teórica de Mijares, el motor de la dramaturgia hipertextual ya no es el conflicto sino el dilema. Son dilemas a los que nos enfrentamos a cada momento los seres del siglo XXI. A los conflictos, dice Mijares, se enfrentan los héroes y los seres paradigmáticos, los cuales quedaron atrapados en el pasado. Es crucial entender que el dilema, a diferencia del conflicto, rompe con el binarismo, pues abre una multiplicidad de posibilidades:

Por qué no hablar mejor de los dilemas del individuo, de esos criterios de decisión que asaltan a las personas a cada paso a lo largo del día y que van de las opciones simples que la propia vida se encarga de automatizar, a las complejas que son o debieran ser, para el dramaturgo, el propósito esencial de análisis, con tal de proporcionar al espectador una pluralidad de elementos [...], de posibilidades de elección, para que sea él, cada uno de los integrantes del público, quien se sienta aludido, se apropie y prolongue la interpretación. Es decir el dilema borra la carga bélica del conflicto. (Galicia 191) En el momento en que esta carga es pospuesta se abre de inmediato la posibilidad de reflexión y, por ende, de refracción. Ahora, para que este ejercicio pueda ser consumado se requiere la suma de miradas de los creadores de la escena y también de los espectadores que se encuentran incluidos en las posibilidades que la dramaturgia hipertextual abre. En efecto, al solicitar la colaboración de los otros, se quiebra la escena teológica tal como fue enunciada por Derrida. La ausencia de acotaciones trasluce el entendimiento de que el texto es medio y no fin. ¿Cómo podrían evadir los dramaturgos la relación con el escenario si en la mayoría de los casos son teatristas en toda la extensión de la palabra? Más todavía, la dramaturgia hipertextual se sustenta en la convención teatral. Aunque las obras tienen rasgos literarios 
o cinematográficos, sus resoluciones están pensadas a partir de los recursos teatrales. La convención escénica es fundamental; sólo así puede entenderse la resolución de tiempos y lugares complejos. Son cronotopos sólo existentes en la mente de los personajes, creadores y lectores/espectadores.

Las estructuras abiertas consideran la pulsión que los humanos tenemos por otorgar sentido, orden y significado. Interpretación que se relaciona con el grupo cultural de pertenencia del receptor y "según la historia personal que se halla tras cada mirada" (Gubern 12). A partir de la multiplicidad expuesta en los textos cada espectador elabora su interpretación. Muy lejos está la dramaturgia hipertextual de establecer una fórmula única que, como la gráfica de composición realista o aristotélica, prevea la reacción del público. Hoy es un hecho que el público tiene una dinámica de vida y un entrenamiento vinculado a la tecnología que impacta su umbral de atención y modifica su percepción y conceptualización de la realidad.

\section{Recursos de la virtualidad y estructuras del hipertexto}

En la dramaturgia hipertextual aparecen recursos y estructuras que a continuación me propongo describir. Para ejemplificar acudo a obras fronterizas, así calificadas tanto por la territorialidad en la cual surgen como por su conformación poética (desdelimitación genérica y entrecruzamientos con otras disciplinas). Cabe advertir que aunque los recursos y estructuras fueron aislados con el fin de exponerlos con claridad, frecuentemente se encuentran superpuestos o imbricados en esta dramaturgia.

Fractal. Es una figura que mantiene su forma aun cuando se le cambie de escala. Para clarificar esta definición, pensemos en las matrioshkas, las muñecas rusas; todas son similares, pero de tamaños distintos. A decir de Eliezer Braun, si se pudiera tener un conjunto muy grande, infinito de muñecas, todas iguales, pero una más pequeña que la anterior, tendríamos un fractal. Es el caso de un objeto que tiene una forma y en una escala infinita la sigue conservando. Por ejemplo, una cadena de montañas o la red de fibras de un corazón se pueden considerar "autosimilares". Asimismo, en las plantas se encuentra este fenómeno de autosimilitud; la hojita que sale del tallo tiene la forma de un helecho completo. Lo que varía es el tamaño. En la literatura podemos ver estas estructuras cuando hay un recurso dentro de otro a distinta escala y a éste le sigue otro y otro al infinito. En la dramaturgia hipertextual, un fractal es la mínima anécdota o el dilema. Como ejemplo, se encuentra la inclusión de un corrido al principio de la obra Apaches de Víctor Hugo 
Rascón Banda. Este constituye el fractal o mínima anécdota a partir de la cual se desarrollará toda la obra. Al lector/espectador se le presenta toda la historia, misma que se irá desplegando autosimilarmente en cada escena.

Personajes múltiples e intercambiables. Son personajes que, como abanicos, abren una vasta gama de facetas, en las cuales el público puede reconocerse. Con esta propuesta se amplían posibilidades; los personajes son vistos como entidades que se despliegan para mostrar diversos roles. No tiene nada que ver con las personalidades disociadas o divididas que estudia la psicología, sino con el desmontar - derrideanamente-los diversos roles o facetas que constituyen al ser. En las obras se distinguen viñetas de conducta y se bocetan estímulos a partir de los personajes. El personaje realista se desintegra para dar paso al múltiple que se muestra simultáneamente en unidad y en diversidad de facetas. Un personaje múltiple es una mujer en tanto es madre, asesina, secretaria, hija, abuela y amiga en diversos tiempos y en distintas situaciones y relaciones. A su vez cada uno de estos roles se diversifica. Los personajes intercambiables ofrecen la posibilidad de transitar por el lugar que ocupa el otro. Un ejemplo concreto de personajes intercambiables serían Polo y Ross de Las perlas de la virgen. Tienen nombres diferentes, pero en cada escena van intercambiando sus roles, y finalmente se trata del mismo ser con aspiración de frontera. En Apaches, de Víctor Hugo Rascón Banda, conquistador y conquistado muestran una alternancia de roles. Hay un intercambio de identidad: la víctima se convierte en victimario y éste en oprimido. El siguiente texto insinúa la alternancia:

Joaquín: Bárbaros que arrancan cabelleras y queman lo que encuentran a su paso.

Vitorio: A su paso lo que encuentran queman, cabelleras arrancan, bárbaros. (186)

Deserere, de Cruz Robles, plantea una víctima de la violencia feminicida. Es un personaje intercambiable ya que la viñeta de víctima aparece en diversas latitudes y tiempos (siglos XXI y XVI y el futuro). No es el personaje el que atraviesa diversos cronotopos sino son diversas viñetas que conforman una categoría o metáfora.

Intertextualidad. La presencia efectiva de un texto, una imagen, una melodía, un discurso (político, histórico, antropológico), o incluso, acciones y gestos. El fragmento sacado de su contexto u obra original adquiere una nueva significación en el entramado al cual se integra. Un ejemplo de intertextualidad 
se encuentra en Border Santo de Virginia Hernández, donde se introducen fragmentos literales de Pedro Páramo y Anacleto Morones de Juan Rulfo y Camino rojo a Sabaiba de Óscar Liera. Un ejemplo de intertextualidad plástica y de acción es Los estanques de Monet de Hermes Iván Díaz. Un asesino en la morgue dice, ante su víctima: "La policía empezó a especular la posibilidad de que yo sea un copycat del egipcio de Ciudad Juárez" (35). El intertexto es una acción que nos envía de inmediato a los casos reales de feminicidios. Sin referirlo de manera explícita, la obra resulta una propuesta creativa que alude estos hechos desde las motivaciones del asesino. Los estanques de Monet propone un entramado del texto dramático con una serie de proyecciones de pinturas de Monet, Goya, Van Gogh, Klimt y otros intertextos. Este proceder apuntala la polifonía de la obra. Otro caso de intertextualidad lo constituyen diversas obras que incorporan canciones y corridos, los cuales resemantizan o resignifican la propuesta escritural.

Videoclip. Más allá de la subordinación que la imagen tiene respecto a la música y la finalidad comercial, en la estructura del videoclip encontramos elementos como fragmentación, discontinuidad, multiplicidad de puntos de vista, repetición y simultaneidad de planos y escenas, con lo cual el videoclip se aparta definitivamente de la estructura lineal. Elipsis, resumen y pausas descriptivas son otros de los elementos que lo componen. Lo que vemos en los videoclips es la exploración de mundos superpuestos, la entrada a otras dimensiones paralelas y la simulación de un tiempo que no nos es ajeno. Las convenciones del videoclip son las que observamos en los textos teatrales: discontinuidad, simultaneidad, retrocesos, fragmentación, etcétera. Si bien el objetivo del videoclip es vender algún producto principalmente musical, existe otro tipo de videoclips:

[En] el discurso del video clip de vanguardia, la ideología se encuentra jugando un rol decisivo para las políticas expresivas, y que los jóvenes, o públicos menos avisados en problemas teóricos, reconocen el llamado d un movimiento centrífugo a las pretensiones globalizadoras, movimiento que podría estar relacionado con las tercas búsquedas de conceptos algo marginados en la actualidad, como la belleza, o de incesante discusión, como la identidad, tradicionales embaucadoras de la linealidad discursiva. (Castro)

El videoclip finalmente resulta audacia estructural que convoca imágenes hiperbólicas. La linealidad es rota en el videoclip; tiempo y lugar no requieren de su inscripción. Príncipe Caballito de Mar, de Medardo Treviño, recrea 
situaciones y dilemas que no tienen un cronotopo específico, ya que ocurren en la mente de un joven que está bajo los efectos de las drogas. Es decir, la mínima anécdota transcurre en un espacio y tiempo virtual.

Talk show. Estructura que presenta diversos testimonios orales ante un hecho. Es un formato extraído de los reality shows televisivos. Su topografía implica un conductor o conductora, testimoniantes y especialistas sobre el tema, así como un público que puede participar o no en el programa. La intervención de los emisores conforma un texto polifónico que orquesta las variadas y múltiples voces que aportan opiniones, información y posición de los involucrados, así como de los especialistas. Esta forma de exposición televisiva ha tenido gran éxito porque refuerza las similitudes que hay entre testimoniantes y teleaudiencia. En la televisión lo que se observa es un encausamiento o juicio por parte del conductor que señala lo que está bien, lo que está mal, e incluso, lo que merece un castigo por parte de las autoridades correspondientes. Aspectos maniqueos que, como hemos explicitado, no se retoman en la dramaturgia hipertextual, pero sí la estructura de exposición con los diversos puntos de vista, tanto de los involucrados como de los especialistas, es decir, se abre a la polifonía y la participación. De esta manera se proporcionan todos los elementos para que sean los espectadores quienes construyan sentido. El mismo dolor, obra de Enrique Mijares, recrea un caso real ampliamente difundido años atrás: la violación de adolescentes. Mijares saca el caso de los medios masivos de comunicación para exponer la profundidad del tema, el impacto a nivel humano de la violencia social que se inscribe en el cuerpo de las mujeres. El mismo dolor retoma la estructura del talk show para incluir la voz de distintos agentes sociales ante el dilema que surge cuando una joven queda embarazada como consecuencia de una violación.

Hipertexto. Es el proceso de navegación que lleva a cabo el autor o el espectador por el laberinto de la creación. Este recorrido no es una secuencia lineal, sino una serie de enlaces o ligas que permiten que cada navegante establezca el rumbo a seguir. Explica Charles Deermer: "Lo que hace que el hipertexto sea hipertexto no es la no-linealidad sino la elección, la interacción del lector para determinar cuál de los diferentes senderos a través de la información disponible es el que toma en cada momento" (sin pag.). El hipertexto ofrece una multiplicidad o laberinto de opciones frente a un tema. A cada momento hay que tomar una decisión; estamos frente al dilema 
que implica qué camino se ha de tomar. Esta es la estructura que retoma la dramaturgia hipertextual. ¿Cómo se explicita en una estructura teatral? Se plantea un problema y se ofrecen diversas opciones para que el público ordene y elija a partir de su singularidad. El hipertexto tiene múltiples caminos virtuales que ayudan a tomar una decisión después del conocimiento de las distintas posibilidades. Cada cuadro o escena es una opción para que el público construya su interpretación sobre los personajes y los fenómenos sociales. Siguiendo esta definición, las obras paradigmáticas serían justamente Las perlas de la virgen de González Dávila y La maraña de Antonio González Caballero, obra en que al final los personajes están al principio. Víctor Hugo Rascón Banda ofrece un ejemplo magistral del hipertexto en El deseo cuando el personaje Víctor enuncia una multiplicidad de posibilidades que quizá habría vivido si Susana no hubiera ido por él a la frontera México-Estados Unidos:

Si yo me hubiera quedado en Cartagena, estaría casado con Yadira, mi novia, tendríamos cinco hijos y lo que yo ganara como chofer no me alcanzaría para nada y estaría amarrado, con doble o triple turno, a lo mejor estaría panzón de tanta cerveza, sin pelo, con una esposa gorda. Si la hubiera abandonado en la puerta de la iglesia, el día de nuestra boda, sus hermanos me habrían perseguido por toda Cartagena y me hubieran encontrado en un hotel de paso. Nos habríamos enfrentado a balazos, no, a navajazos, y yo habría matado al mayor y habría ido a la cárcel. (237-38)

Polisemia. Planteamos la polisemia tal como la define Roman Gubern, es decir, la coexistencia de varios significados distintos en un mismo discurso o representación. La dramaturgia hipertextual retorna a la idea del espectador o lector como intérprete. Abre opciones y otorga al espectador un rol coautoral. Al plantear diversas posibilidades u opciones frente al dilema, ya sea a través del hipertexto, de una estructura irradiante o de talk show, lo que se expone son diversas posibilidades para que el espectador - en este caso me refiero con toda intención a un individuo y no al conjunto que implica "el público"arme el significado de la representación. Como ejemplo de polisemia, Larisa López en Historias para mal dormir deposita a cinco mujeres en un espacio estremecedor, donde un líquido cae incesantemente, una escalera eléctrica no deja de ascender y una pared que sostiene gavetas transparentes contenedoras de zapatos y de cadáveres femeninos se constituye como una presencia amenazante. Este espacio ya de por sí abigarrado apunta un presente continuo 
interminable. Entre sombras, varios cadáveres con las cuencas vacías evocan las pinturas de Francis Bacon. Las cinco mujeres habitan un espacio múltiple difuso que lo mismo es un limbo que diversas recámaras, un aeropuerto o centro comercial. Ellas en su condición de no-vivas llevan a cabo actos que mixturan la reflexión y el no-sentido. Las imágenes son tan complejas que están abiertas a diversas interpretaciones. A decir de Enrique Mijares, son:

Víctimas y victimarias a la vez, sadomasoquistas, pues en esta alegoría del terror las mujeres padecen las consecuencias de un status quo que ellas mismas se han encargado de fundar y robustecer y que las reduce a la condición de objetos de deseo, de su propio deseo insatisfecho, exacerbado, recidivante, donde nadie las ve, enterradas, muertas en vida, mutiladas, encerradas, refugiadas en la ficticia intimidad del clóset, debajo de las sábanas, prisioneras de una escalera que, como las arquitecturas de Escher, está condenada a un movimiento continuo, a contracorriente, sin principio ni fin. ("Taller Tamaulipeco" 21)

Multifocalidad. Es la diversidad de puntos de vista. Apela al ejercicio del libre albedrío del espectador. Lo que el dramaturgo expone es todo lo que sabe acerca del tema. No podemos decir en este sentido que el espectador recibe un mensaje unívoco, ya que el dramaturgo, al multiplicar las opciones, abre paso a la ambigüedad. En la multiplicidad lo que se encuentra es la heterogeneidad. Este recurso es utilizado para abordar el asunto desde diversas perspectivas o ángulos. La verdad unívoca no existe; lo que se plantea es la perspectiva de cada uno de los involucrados. Así aparece una estructura irradiante, donde una mínima anécdota se ramifica en función de las distintas versiones. La multifocalidad conduce a la estructura hipertextual. Expedientes de odio, de Selfa Chew (En la frontera Norte), expone una multiplicidad de posibilidades de concreción de la asimetría sexual, étnica, religiosa y cultural. La obra expone la relación amor-odio de diversas parejas signadas por los radicalismos y la intolerancia. Se discrimina por la complexión, la raza, las creencias, el género, la religión, etcétera. Los expedientes están precedidos por una numeración que denota su discontinuidad y la dimensión del síntoma.

Estructura irradiante. El término "irradiante" parte de las asociaciones que el cerebro humano establece como líneas de pensamiento que se disparan a partir de un número infinito de datos. Por ejemplo, una persona come, ve la tele, escucha el ruido de los vecinos, percibe un olor y siente la elevada 
temperatura, todos datos que son reflejo de estructuras a partir de redes neuronales que constituyen la arquitectura física del cerebro. El pensamiento irradiante es: "una idea o imagen central que irradia una serie de asociaciones o enlaces con otras, que a su vez generan sus propias conexiones y así hasta el infinito" (Sánchez Santillán). Este funcionamiento por asociaciones es lo que constituye la irradiación, misma que puede encontrase en la estructura de los mapas mentales. El deseo de Víctor Hugo Rascón Banda tiene una estructura irradiante que nos muestra las diversas ramificaciones que implica la convivencia - amor-odio - entre dos naciones representadas por una estadounidense y un colombiano. Tal como está construida la obra, remite a este tipo de estructura, pues no hay un encadenamiento cronológico, sino la exposición temática a partir de un centro: la relación afectiva entre dos culturas. De ahí se desprenden: las diferencias, las visiones del mundo y los juegos de poder. Luego, de éstos se derivan ideas asociadas: equívocos, idioma, diferencias sociales o gastronómicas, la situación económica y la presencia de los sistemas jurídicos. Las estructuras irradiantes también aluden a la red de nervaduras de una hoja, donde de una línea divergen otras que constituyen posibilidades innumerables.

Teoría del caos. Esta teoría no sólo ha desestabilizado conceptos científicos, sino que ha impactado nuestra propia percepción del universo. Hoy sabemos que muchos fenómenos de la naturaleza y diversos comportamientos sociales tienen un funcionamiento complejo no lineal cambiante y paradójicamente inalterable. La observancia de este desorden nos ha llevado a replantear el pensamiento y la percepción. "La teoría del caos procura una aproximación a la comprensión de la realidad más acorde con las características de la realidad a la que se aplica... por lo que se conformaría como la gramática de una nueva narración acerca de la realidad, fundamentalmente de la realidad compleja" (Colom Cañellas). Esta nueva manera de entender el devenir de la naturaleza y por lo tanto del hombre, es de lo que está impregnada esta dramaturgia, la cual, como hemos observado, apela a la complejidad y subvierte la linealidad. ¿Cómo tratar de explicar una obra como Príncipe Caballito de Mar? Como indiqué anteriormente, se trata de una obra que sucede en el delirio alucinatorio de un joven. La sucesión de espacios y tiempos alude justamente al caos y de ningún modo a la linealidad.

El mundo que habitamos es esencialmente un mundo no lineal. Los científicos se preguntan cómo sus antecesores no lo advirtieron antes. Sin embargo, la posibilidad de entender la teoría del caos y los fractales se dio 
una vez que las computadoras pudieron colaborar con el hombre en el diseño de las ecuaciones y las representaciones icónicas del caos y el fractal. Son estas consideraciones las que permean nuestra vida diaria e impactan a la dramaturgia hipertextual, la cual, al referir un mundo alterno -el de la ficción-, abre posibilidades inéditas.

El tiempo. De varias maneras y a través de los distintos recursos se ha aludido al uso del tiempo en la dramaturgia hipertextual, por ejemplo, al hablar de la no linealidad y la discontinuidad. La virtualización permite romper con la lógica del lugar y del tiempo para situarse en un no-lugar y no-tiempo. Las obras que comprenden nuestro corpus plantean tiempo expandido, dilatado y la especulación atemporal (no-tiempo). Como es factible observar, el tiempo en la dramaturgia hipertextual no concibe la rigidez, pues abre camino hacia la representación del desorden y lo inestable.

La convención teatral. Todos los recursos usados en la dramaturgia hipertextual tienen como elemento aglutinador la convención, ya que es imprescindible que el público crea lo que se le cuenta. No es suficiente un espacio escénico, actores y público, pues es diferente alguien que observa en la calle una acción que no tiene una finalidad estética que lo que sucede cuando se crea una ficción que es asumida como "verdadera" por los espectadores y creadores. La convención es el pacto aceptado en el que se establecen las condiciones del juego. Cada elemento en el teatro es una convención: tiempo, espacio. Basta con invocar un espacio para que el espacio aparezca. Los personajes y las situaciones son ficticios, no obstante, como señala Jorge Volpi: "si la ficción es una herramienta tan poderosa para explorar la naturaleza-y en especial la naturaleza humana-, es porque la ficción también es realidad" (31). El mismo mecanismo para aprender la realidad es efectuado por el cerebro para aprender la ficción, señalan los científicos. Es pensamiento real-virtual.

A excepción de las obras de Víctor Hugo Rascón Banda, Medardo Treviño, Virginia Hernández y Enrique Mijares, el resto de los textos dramáticos citados en este ensayo son producto de los distintos talleres de dramaturgia hipertextual que Mijares ha impartido en México desde $2003 .{ }^{2} \mathrm{El}$ espectro de obras hipertextuales se aproxima a los dos centenares. Algunas de ellas han sido llevadas a escena, otras han sido analizadas, pues constituyen atractivos universos para ser repensadas desde sus implicaciones temáticas y poéticas. La frontera como territorio entraña la densidad de estas obras. Aunque los espectadores no reconozcan el cambio de paradigma, sí reconocen 
su cercanía con la nueva narrativa cinematográfica y las posibilidades inestables del internet, la ciencia y la tecnología. Consecuentemente, las estructuras provocan que los espectadores construyan sentido sobre las problemáticas expuestas. En la frontera norte se ensaya-lo cual constituye un ejercicio de virtualización-la dramaturgia contemporánea que rompe paradigmas.

\section{Centro Nacional de Investigación Teatral "Rodolfo Usigli"}

\section{Notas}

1 En las clases de teorías dramáticas se enseña que a lo largo de la humanidad sólo ha habido cuatro tipos de conflictos: El hombre en contra de los dioses; El hombre contra sí mismo; El hombre contra la sociedad y viceversa; Todos contra todos (la lucha de todos los personajes entre sí por sus respectivos intereses, contradicciones y caracteres).

2 Estos talleres han generado las siguientes publicaciones: Dramaturgia de Cuernavaca. Teatro de Frontera 20. Durango: UJED-Espacio Vacío, 2008; Dramaturgia de Chihuahua. Teatro de Frontera 24. Durango: UJED-Espacio Vacío, 2010; Dramaturgia de Durango. Durango: Instituto de Cultura de Durango, 2007; Dramaturgia de Durango II. Durango: ICED, 2008; Dramaturgia de Durango III. Durango: ICED, 2008; Dramaturgia joven de Nuevo Laredo. Tamaulipas: ITCA, 2007; Dramaturgia de Hermosillo. Durango: UJED, 2007; Dramaturgia de la Sierra de Sonora. Teatro de Frontera 17. Durango: UJED-Espacio Vacío, 2006; Dramaturgia de Monterrey. Teatro de Frontera 18. Durango: UJED-Espacio Vacío, 2007; Dramaturgia de Saltillo. Teatro de Frontera 21. Durango: UJED-Espacio Vacío, 2008; En la frontera Norte, Ciudad Juárez y el teatro. Chihuahua: Instituto Chihuahuense de Cultura, 2008; Heber Banda et al. Teatro de Frontera 10. UJED-Espacio Vacío, 2003; Teatro joven de Tamaulipas. Tamaulipas: ITCA, 2003; Veracruz. Dramaturgia del Puerto. Teatro de Frontera 19. Durango: UJED-Espacio Vacío, 2007.

\section{Fuentes consultadas}

Braun, Eliezer. Caos, fractales y cosas raras. México: Fondo de Cultura Económica / Secretaría de Educación Pública / Conacyt, 1996.

Castro, Holanda. "El discurso caótico de los videoclips". Ponencia presentada en el $16^{\circ}$ Congreso Internacional sobre Expresión y Representación de Parodia e Imitación en Literatura, Arte y Cine. University of West Georgia, Atlanta, 2001.

Chew, Selfa. Expedientes del odio. En la frontera norte, Ciudad Juárez y el teatro. Ed. Enrique Mijares. Chihuahua: Instituto Chihuahuense de la Cultura/ Universidad Autónoma de Ciudad Juárez, 2003. 43-85.

Colom Cañellas, Antonio J. "Teoría del caos y práctica educativa". http://dialnet. unirioja.es/servlet/articulo?codigo=2554834 26 de septiembre de 2011. 
Deermer, Charles. “¿Qué es el hipertexto?” http:www.//ucm.es/info/especulo/hipertul/ deermer.html. 26 de septiembre de 2011.

Derrida, Jacques. La escritura y la diferencia. Barcelona: Anthropos, 1989.

Díaz Ceniceros, Hermes Iván. Los estanques de Monet. Dramaturgia de Hermosillo. Ed. Enrique Mijares. Durango: Universidad Juárez del Estado de Durango, 2007. 35-42.

Galicia, Rocío . "La dramaturgia norteña, un archipiélago de circunstancias: entrevista al dramaturgo Enrique Mijares". Latin American Theatre Review 40.1 (2006): 187-92.

González Dávila, Jesús. Las perlas de la virgen. Jesús González Dávila. Durango: UJED / Espacio Vacío, 1996. 143-93.

Gubern, Roman. Del bisonte a la realidad virtual. La escena y el laberinto. Barcelona: Anagrama, 1996.

Hernández, Virginia. Border Santo. Virginia Hernández. Durango: UJED / Espacio Vacío, 2005. 161-201.

Lehmann, Han-Thies. "Algunas notas sobre el teatro posdramático, una década después". Repensar la dramaturgia. Errancia y transformación. Murcia: Centro Párraga, Centro de Documentación y Estudios Avanzados de Arte Contemporáneo, 2010. 309-29.

."El teatro posdramático: una introducción". Telón de fondo (diciembre 2010). http://www.telondefondo.org/numeros-anteriores/numero12/articulo/318/ el-teatro-posdramatico-una-introduccion-.html 27 de enero de 2011.

López, Larisa. Historias para mal dormir. Teatro joven de Tamaulipas. Ciudad Victoria, Tamaulipas: Gobierno del Estado de Tamaulipas/Instituto Tamaulipeco para la Cultura y las Artes, 2003. 93-112.

Mijares, Enrique. El mismo dolor. Espinazo del diablo. Ciudad Victoria: Tequio, 2003. . Entrevista personal con la autora. 4 de octubre de 2004.

. "Las perlas a la virgen. El teatro de frontera de Jesús González Dávila". La realidad virtual del teatro mexicano. México: Juan Pablos / Instituto Municipal del Arte y la Cultura / Fondo Municipal para la Cultural y las Artes de Durango / Conaculta-Fonca, 1999. 71-83.

. "Taller Tamaulipeco de Dramaturgia Virtual". Teatro joven de Tamaulipas. Ciudad Victoria, Tamaulipas: Gobierno del Estado de Tamaulipas/Instituto Tamaulipeco para la Cultura y las Artes, 2003. 15-23.

Partida Tayzan, Armando. Modelos de acción dramática: aristotélicos y no aristotélicos. México: Universidad Nacional Autónoma de México / Itaca, 2004.

Rascón Banda, Víctor Hugo. Apaches. Umbral de la memoria. Otras voces, otras fronteras. Tomo V. Chihuahua: Instituto Chihuahuense de Cultura, 2010. 179-226. 
. El deseo. Umbral de la memoria. Otras voces, otras fronteras. Tomo V. Chihuahua: Instituto Chihuahuense de Cultura, 2010. 227-65.

Ricoeur, Paul. Freud: una interpretación de la cultura. México: Siglo XXI, 1990.

Robles, Cruz. Deserere. Dramaturgia de Hermosillo. Ed. Enrique Mijares. Durango: Universidad Juárez del Estado de Durango, 2007. 109-16.

Sánchez Santillán, Norma y Rubén Sánchez Trejo. "Una herramienta sencilla y eficaz: los mapas mentales". http://www.izt.uam.mx/contactos/n59ne/mapas.pdf. 25 de septiembre de 2011.

Schifter, Isaac. La ciencia del caos. México: Fondo de Cultura Económica / Secretaría de Educación Pública / Conacyt, 2003.

Treviño, Medardo. Príncipe caballito de mar. Medardo Treviño. Durango: UJED / Espacio Vacío, 2000. 157-74.

Volpi, Jorge. Leer la mente. El cerebro y el arte de la ficción. México: Alfaguara, 2011. 
